simple rules. These rules, which are identical in form with those already worked out for oxidoreductions and phosphorylations (Dixon, 1949), enable deductions about the nature of the enzymesubstrate or enzyme-inhibitor combination and the ionization constants of the groups involved to be drawn from the effect of $\mathrm{pH}$ upon the affinities.

I am grateful to Dr R. K. Morton for allowing me to quote his unpublished experiments on phosphatase.

\title{
REFERENCES
}

Briggs, G. E. \& Haldane, J. B. S. (1925). Biochem. J.19, 338. Chance, B. (1952). J. biol. Chem. 194, 483.

Delory, G. E. \& King, E. J. (1943). Biochem. J. 37, 547.

Dixon, M. (1949). Multi-enzyme Systems. Cambridge University Press.

Dixon, M. (1953). Biochem. J. 53, 329.

Folley, S. J. \& Kay, H. D. (1935). Biochem. J. 29, 1837.

Hase, E. (1952). J. Biochem., Tokyo, 39, 259.

Howell, S. F. \& Sumner, J. B. (1934). J.biol. Chem. 104, 619.

Jacobsen, E. (1933). Biochem. Z. 267, 89.

Josephson, K. (1924). Hoppe-Seyl. Z. 134, 50.

Lineweaver, H. \& Burk, D. (1934). J. Amer. chem. Soc. 56, 658.
Lowry, O. H., Bessey, O. A. \& Crawford, E. J. (1949). J. biol. Chem. 180, 399.

Massey, V. (1953). Biochem. J. 55, 172.

Michaelis, L. (1930). Oxidation-Reduction Potentials. Philadelphia and London: J. B. Lippincott Co.

Michaelis, L. \& Menten, M. L. (1913). Biochem. Z. 49, 333.

Mohamad, S. M. \& Greenberg, D. M. (1945). Arch. Biochem. $8,365$.

Morton, R. K. (1952). Ph.D. Thesis, Cambridge University. Quastel, J. H. (1926). Biochem. J. 20, 166.

Slater, E. C. \& Bonner, W. D. (1952). Biochem. J. 52, 185.

\section{The Determination of Enzyme Inhibitor Constants}

\author{
By M. DIXON \\ Biochemical Laboratory, University of Cambridge
}

(Received 28 October 1952)

The Michaelis constant, $K_{m}$, that is to say the equilibrium constant of the reversible combination of an enzyme with its substrate, is most conveniently determined by Lineweaver \& Burk's (1934) method of plotting. The great advantage of this method is that by plotting $1 / v$ against $1 / s$ it makes it possible to represent the Michaelis equation

$$
v=\frac{V s}{K_{m}+s}
$$

by a straight line. Here $v$ is the reaction velocity with the substrate concentration 8 , and $V$ is the maximum velocity obtained at high substrate concentrations. Lineweaver \& Burk calculate $K_{m}$ from the slope of the line and its intercept on the vertical axis, but there is a simpler method which they do not mention, namely to produce the line to the left of the vertical axis, when it will cut the baseline at a point giving $-1 / K_{m}$, as shown in Fig. 1 . This is easily shown by putting $1 / v=0$ in the reciprocal form of equation (1), namely

$$
\frac{1}{v}=\frac{K_{m}}{V} \frac{1}{s}+\frac{1}{V},
$$

which then gives $1 / s=-1 / K_{m}$.
The inhibitor constant, $K_{i}$, that is to say the equilibrium constant of the reversible combination of the enzyme with a competitive inhibitor, has hitherto usually been obtained by calculation from the Michaelis equation for a competitive system

$$
v=\frac{V_{s}}{K_{m}\left(1+\frac{i}{K_{i}}\right)+s},
$$

where $i$ is the inhibitor concentration. For this calculation the effect on the velocity of varying independently both $s$ and $i$ must be determined.

There is, however, a simple graphical method of determining $K_{i}$ which, as far as the writer is aware, has not been described previously. If $1 / v$ is plotted against $i$, keeping 8 constant, a straight line will be obtained, and if this is done at two different substrate concentrations $\boldsymbol{s}_{1}$ and $\boldsymbol{s}_{2}$ the lines will cut one another at a point on the left of the vertical axis, as shown in Fig. 2. This point lies at $-K_{i}$, which can therefore be read off directly.

The proof is as follows. Each line represents the reciprocal form of equation (2), namely

$$
\frac{1}{v}=\frac{K_{m}}{V s}+\frac{1}{V}+\frac{K_{m}}{V s} \frac{i}{K_{i}} .
$$


At the point of intersection $1 / v$ and $i$ will be the same for both lines, as also will $V$ since the inhibition is competitive. Therefore

$$
\begin{aligned}
\frac{K_{m}}{s_{1}}+1+\frac{K_{m}}{s_{1}} \frac{i}{K_{i}} & =\frac{K_{m}}{s_{2}}+1+\frac{K_{m}}{s_{2}} \frac{i}{K_{i}}, \\
\frac{1}{s_{1}}\left(1+\frac{i}{K_{i}}\right) & =\frac{1}{s_{2}}\left(1+\frac{i}{K_{i}}\right) .
\end{aligned}
$$

or

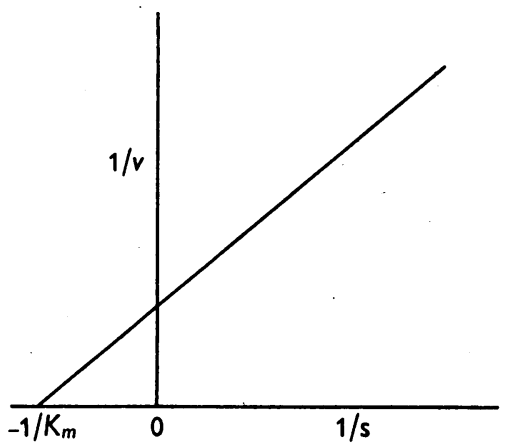

Fig. 1. Determination of $K_{m}$.

This can only be true if either $s_{1}=s_{2}$ or $i=-K_{i}$.

If desired, $K_{m}$ can also be determined from the same plot when $K_{i}$ has been found, for each line cuts the base-line at a value of $i$ equal to $-K_{i}\left(8 / K_{m}+1\right)$.

Alternatively, if $K_{m}$ has already been determined by a Lineweaver plot in the absence of inhibitor, it is only necessary to carry out inhibition experiments at one substrate concentration. The intersection point giving $K_{i}$ lies at a height of $1 / V$, as may be seen by putting $i=-K_{i}$ in equation (3), and this quantity will already have been given by the Lineweaver plot (intersection with the axis for $1 / 8=0$ ). It is therefore only necessary to draw a horizontal line at a height of $1 / V$, and the point where it intersects the inhibitor line will give $-K_{i}$. This procedure, however, must only be used for competitive cases.

The case of a non-competitive inhibitor is shown in Fig. 3. Here the lines do not cross, but they meet at a point on the base line which again gives $-K_{i}$. This is easily seen on putting $1 / v=0$ in the reciprocal non-competitive equation

$$
\frac{1}{v}=\frac{1}{V}\left(1+\frac{K_{m}}{s}\right)\left(1+\frac{i}{K_{i}}\right) .
$$

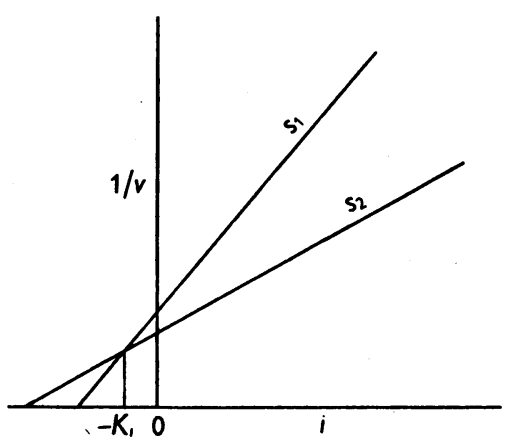

Fig. 2. Determination of $K_{i}$ (competitive inhibition).

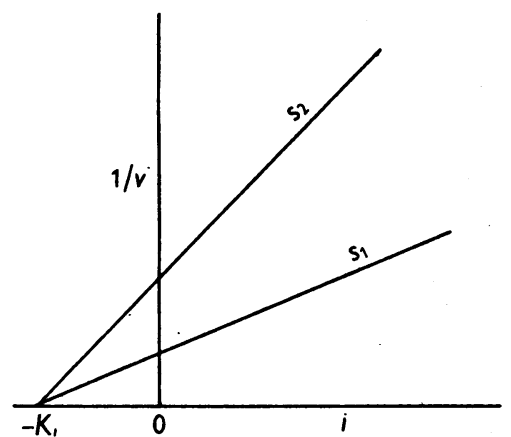

Fig. 3. Determination of $K_{i}$ (non-competitive inhibition).

\section{SUMMARY}

A simple graphical method for determining enzyme inhibitor constants is described.

\section{REFERENCE}

Lineweaver, H. \& Burk, D. (1934). J. Amer. chem. Soc. 56, 658. 